\title{
PENGARUH PENGENDALIAN INTERNAL DAN MORALITAS INDIVIDU TERHADAP KECURANGAN AKUNTANSI
}

\author{
Dionisia Nadya Sri Damayanti \\ Prodi Akuntansi Universitas Negeri Yogyakarta \\ dionisianadya31@gmail.com
}

\begin{abstract}
Abstrak : Pengaruh Pengendalian Internal Dan Moralitas Individu Terhadap Kecurangan Akuntansi. Penelitian ini bertujuan untuk mendapatkan bukti adanya: Perbedaan antara individu dalam kondisi terdapat elemen Pengendalian Internal dan tidak terdapat elemen Pengendalian Internal dalam melakukan Kecurangan Akuntansi; Perbedaan antara individu yang mempunyai level Moralitas Individu tinggi dan level Moralitas Individu rendah dalam melakukan Kecurangan Akuntansi; dan Interaksi antara Pengendalian Internal dengan Moralitas Individu dalam mempengaruhi Kecurangan Akuntansi. Penelitian ini menguji pengaruh Pengendalian Internal dan Moralitas Individu terhadap Kecurangan Akuntansi dengan menggunakan desain eksperimen faktorial 2x2. Populasinya adalah seluruh pegawai bagian keuangan dan akuntansi UNY yaitu 82 partisipan, namun yang dapat diolah sebanyak 73 partisipan. Hasil penelitian menunjukkan bahwa: terdapat perbedaan antara individu pada kondisi terdapat elemen Pengendalian Internal dan tidak terdapat elemen Pengendalian Internal dalam melakukan Kecurangan Akuntansi; terdapat perbedaan antara individu yang memiliki level Moralitas Individu tinggi dan level Moralitas Individu rendah dalam melakukan Kecurangan Akuntansi; dan terdapat interaksi antara Pengendalian Internal dengan Moralitas Individu dalam mempengaruhi Kecurangan Akuntansi.
\end{abstract}

Kata kunci: Pengendalian Internal, Moralitas Individu, Kecurangan Akuntansi

Abstract : The Effect of Internal Controls and Individual Morality on Fraud. The purpose of this study obtained evidence whether there were : Differences among individuals in both present or absent Internal Control element condition in the tendency to commit Fraud; Differences among individuals who had a high levels of Individual Morality reasoning and low level Individual Morality reasoning in the tendency to commit Fraud; also an Interaction between Individual Morality and Internal Controls to effect Fraud. This study examined the effect of Internal Controls and Individual Morality on Fraud with $2 \times 2$ factorial experimental design. The population was the finance and accounting employees of Yogyakarta State University with 82 participants and the data that could be processed was 73 participants. The results showed that: there were differences among individuals in both present or absent Internal Control element condition in the tendency to commit Fraud; there were differences among individuals who had a high levels of Individual Morality reasoning and low level Individual Morality reasoning in the tendency to commit Fraud; also there were an Interaction between Individual Morality and Internal Controls to effect Fraud.

Keywords : Internal Control, Individual Morality, Fraud

\section{PENDAHULUAN}

Dunia akuntansi yang kian

berkembang tidak hanya membawa pengaruh baik untuk masyarakat, namun juga membawa pengaruh buruk seperti masalah kecurangan (fraud). Adapun Associations of Certified Fraud
Examinations (2014) mengklasifikasikan Kecurangan Akuntansi dalam tiga kategori utama yaitu kecurangan laporan keuangan (financial statement fraud), penyalahgunaan aset (asset misappropiation) dan korupsi (corruption). Salah satu bentuk kecurangan atau fraud yang sering terjadi di Indonesia 


\section{JURNAL NOMINAL / VOLUME V NOMOR 2 / TAHUN 2016}

adalah korupsi. Indonesia Corruption Watch atau ICW (2013) mengemukakan bahwa dari tahun 2003-2013, terjadi kasus korupsi pendidikan yang telah diungkap para penegak hukum dengan indikasi kerugian negara sebesar Rp 619,0 miliar dari total 296 kasus.

Sistem Pengendalian Internal dapat mempengaruhi terjadinya kasus penyimpangan di Indonesia dan menjadi upaya yang perlu dilakukan dalam mengantisipasi Kecurangan Akuntansi yang mungkin terjadi di dalam suatu entitas usaha. Sistem Pengendalian Internal merupakan sebuah sistem yang terdiri dari prosedur dan pembentukan kebijakan tertentu yang telah direncanakan sebelumnya agar manajemen semakin yakin dalam rangka usaha pencapaian tujuan dan sasaran perusahaan atau entitas tersebut (Elder, Randal J. et al., 2012:316).

Cressey (1951) dalam Albrecht (2014) telah menyatakan tentang teori segitiga kecurangan (fraud triangle) pada penelitian sebelumnya, yaitu bahwa Kecurangan Akuntansi disebabkan oleh dorongan/tekanan (pressure), kesempatan (opportunity), dan rasionalisasi (razionalization). Albrecht (2014) mengganti faktor rasionalisasi dari teori fraud triangle milik Cressey, dengan personal integrity agar lebih mudah diobservasi. Integritas personal (personal integrity/character) berkaitan dengan kode etik personal milik tiap individu. Integritas personal dapat lebih mudah diobservasi melalui Teori Perkembangan Moral yang akan mengacu pada level penalaran Moral Individu.

Moralitas Individu akan dijelaskan dalam level penalaran moral individu, serta akan berpengaruh pada perilaku etis mereka (Puspasari, 2012). Moral merupakan hal yang sesuai dengan keyakinan umum yang diterima masyarakat, berkaitan dengan penilaian norma tindakan manusia. Semakin tinggi level penalaran Moral Individu, maka akan semakin cenderung untuk tidak melakukan Kecurangan Akuntansi (Wilopo, 2006 dalam Puspasari, 2012). Salah satu Teori Perkembangan Moral yang sering digunakan dalam penelitian tentang etika seseorang adalah model Kohlberg. Kohlberg (1971) menjelaskan bahwa moral berkembang melalui tiga tahapan, yaitu tahapan pre-conventional, tahapan conventional dan tahapan post-conventional.

Transaksi-transaksi yang diurus oleh pengelola aset di bagian keuangan dan akuntansi pada Perguruan Tinggi Negeri (PTN) masih rawan terjerat kasus korupsi karena sistem Pengendalian Internal universitas yang lemah (kabarkorupsi.com, 2014). Menurut Zaenur Rohman, peneliti Pusat Kajian Anti Korupsi Universitas Gadjah Mada (PUKAT-UGM) dalam kabarkorupsi.com (2014), berdasarkan data dari Trend Corruption Report (TCR) 


\section{JURNAL NOMINAL / VOLUME V NOMOR 2 / TAHUN 2016}

PUKAT, bahwa selama semester I (JanuariJuni) 2014, terdapat 10 orang tersangka korupsi di sektor pendidikan tinggi. Hal ini menunjukkan bahwa sistem Pengendalian Internal di universitas belum berjalan sebagaimana mestinya. Selain itu, tingkat korupsi di Daerah Istimewa Yogyakarta (DIY) menduduki peringkat 10 dari jumlah 33 provinsi di Indonesia, akibat penyelesaian kasus korupsi di DIY yang cenderung berlarut-larut dan bahkan sering dihentikan, meski belum terselesaikan sepenuhnya (Olivia, 2010). Dengan demikian, terjadinya Kecurangan Akuntansi di PTN terutama di wilayah DIY masih dikhawatirkan dapat terjadi.

Berdasarkan uraian di atas, penelitian ini bertujuan untuk menganalisis elemen Pengendalian Internal (ada dan tidak ada) dan level Moralitas Individu (tinggi dan rendah) sebagai penyebab terjadinya Kecurangan Akuntansi dengan studi eksperimen pada Universitas Negeri Yogyakarta di bagian keuangan dan akuntansi, sebagai salah satu divisi yang berkaitan dengan transaksi keuangan dalam Perguruan Tinggi Negeri (PTN). Peneliti tertarik menggunakan objek tersebut karena Universitas Negeri Yogyakarta merupakan salah satu entitas akuntansi dari Kementerian Riset, Teknologi dan Pendidikan Tinggi yang mempunyai kewajiban untuk menyelenggarakan akuntansi dan laporan pertanggungjawaban atas pelaksanaan Anggaran Pendapatan dan Belanja Negara dalam sektor pendidikan.

\section{METODE PENELITIAN}

\section{Jenis Penelitian}

Penelitian ini menggunakan desain eksperimen kuasi (quasi experiment) karena tidak menggunakan sampel (penelitian populatif) dan peneliti menggunakan eksperimen lapangan sebab tidak mungkin menempatkan subjek penelitian dalam situasi laboratorik murni yang sama sekali bebas dari pengaruh lingkungan sosial selama diberikan perlakuan eksperimental. Desain ini digunakan ketika desain eksperimen murni tidak dapat digunakan, seperti yang mungkin terjadi dalam keadaan lapangan, misalnya di tempat kerja dan sekolah (Gould, 2002). Populasi dalam penelitian ini terdiri dari 82 orang pegawai bagian keuangan dan akuntansi di Universitas Negeri Yogyakarta. Partisipan yang terdiri dari 82 orang tersebut akan mendapatkan soal kasus dalam dua kondisi tersebut dengan simple randomization melalui undian dengan mengacak soal yang diberikan.

\section{Tempat dan Waktu Penelitian}

Penelitian ini dilaksanakan di Universitas Negeri Yogyakarta pada bagian Keuangan dan Akuntansi. Waktu penelitian dilakukan pada bulan Januari 2016-Februari 2016. 


\section{JURNAL NOMINAL / VOLUME V NOMOR 2 / TAHUN 2016}

\section{Target/Subjek Penelitian}

Populasi dalam penelitian ini adalah seluruh pegawai pada bagian keuangan dan akuntansi yang bekerja di Universitas Negeri Yogyakarta, baik karyawan tetap maupun kontrak. Penelitian ini termasuk penelitian populatif yang berarti bahwa penelitian ini tidak menggunakan sampel. Populasi diambil seluruhnya untuk dijadikan partisipan penelitian karena karena jumlah pegawai bagian keuangan dan akuntansi UNY relatif kecil yaitu 82 orang. Hal ini bertujuan untuk mengantisipasi tingkat pengembalian kuisioner yang rendah. Jumlah data partisipan yang dapat digunakan dalam penelitian ini adalah 73 data partisipan.

\section{Prosedur}

Desain eksperimen faktorial $2 \times 2$ digunakan penelitian ini untuk menguji pengaruh Pengendalian Internal dan Moralitas Individu terhadap Kecurangan Akuntansi. Menurut Gould (2002:302) penelitian ini termasuk penelitian eksperimen dengan desain faktorial (multifaktor) karena meneliti dua variabel independen yang kemudian disusun bersama-sama untuk mengkaji pengaruh tiap variabel maupun interaksinya terhadap variabel dependen. Skema yang terdapat pada desain faktorial berupa matriks dengan kotak yang terpisah untuk tiap kombinasi perlakuan variabel independen.
Variabel dependen dalam penelitian ini adalah Kecurangan Akuntansi, sedangkan variabel independennya adalah Pengendalian Internal (terdapat dan tidak terdapat elemen Pengendalian Internal) dan Moralitas Individu (level Moralitas Individu tinggi dan rendah). Desain eksperimen faktorial $2 \times 2$ dapat dilihat pada tabel 1 sebagai berikut:

Tabel 1. Desain Eksperimen Faktorial

\begin{tabular}{llc}
\hline \multirow{1}{*}{$\begin{array}{c}\text { Pengendalian } \\
\text { Internal }\end{array}$} & \multicolumn{2}{c}{$\begin{array}{c}\text { Level Penalaran } \\
\text { Moral }\end{array}$} \\
\cline { 2 - 3 } & Rendah & Tinggi \\
\hline Tidak Ada & Grup 4 & Grup 2 \\
\hline Ada & Grup 3 & Grup 1 \\
\hline
\end{tabular}

Peneliti mengamati kecenderungan individu melakukan Kecurangan Akuntansi dengan membagi partisipan ke dalam empat grup:

a. Grup 1: Kelompok dalam kondisi terdapat elemen Pengendalian Internal dengan level Moralitas Individu tinggi

b. Grup 2: Kelompok dalam kondisi tidak terdapat elemen Pengendalian Internal dengan level Moralitas Individu tinggi

c. Grup 3: Kelompok dalam kondisi terdapat elemen Pengendalian Internal level Moralitas Individu rendah

d. Grup 4: Kelompok dalam kondisi tidak terdapat elemen Pengendalian Internal dengan level Moralitas Individu rendah

Grup dibagi berdasarkan kondisi kasus yang diterima dan hasil skor level penalaran Moralitas Individu dari soal kasus yang 
dibagikan kepada partisipan. Partisipan akan diberikan soal penugasan pertama terkait kecenderungan untuk melakukan Kecurangan Akuntansi dalam dua kondisi, yaitu terdapat elemen Pengendalian Internal (kelompok eksperimen) dan tidak terdapat elemen Pengenalian Internal (kelompok kontrol). Partisipan eksperimen akan mendapatkan soal kasus dalam dua kondisi tersebut secara acak melalui undian.

Selanjutnya partisipan akan menjawab soal penugasan kedua tentang dilema etika, kemudian partisipan diberi pertanyaan-pertanyaan untuk mengukur level penalaran Moralitas Individu tersebut berdasarkan skor yang diperoleh. Partisipan yang mendapat kasus terdapat elemen Pengendalian Internal dengan level Moralitas Individu tinggi akan masuk dalam grup 1, sedangkan yang memiliki level Moralitas Individu rendah masuk dalam grup 3. Sementara itu partisipan yang mendapat kasus tidak terdapat elemen Pengendalian Internal dengan level Moralitas Individu tinggi akan masuk dalam grup 2, sedangkan yang memiliki level Moralitas Individu rendah masuk dalam grup 4.

\section{Data, Intrumen, dan Teknik Pengumpulan \\ Data}

Data dalam penelitian ini terdiri dari data kuantitatif dan data kualitatif yang dikuantitatifkan agar dapat diproses lebih lanjut dalam statistik (Mudrajad Kuncoro, 2013:145). Data kuantitatif terdapat pada variabel terikat Kecurangan Akuntansi yang diukur dari Skala Likert 1-10 digunakan untuk mengukur respons dari partisipan dalam kasus tentang Kecurangan Akuntansi. Data kualitatif yang dikuantitatifkan terdapat pada variabel bebas pertama yaitu Pengendalian Internal yang terdiri dari dua kondisi dalam soal kasus, yaitu tidak terdapat elemen Pengendalian Internal (yang diberi kode 1) dan terdapat elemen Pengendalian Internal (yang diberi kode 2). Sementara itu, data kualitatif yang dikuantitatifkan juga terdapat pada variabel bebas kedua yaitu Moralitas Individu melalui 6 butir instrumen dengan Skala Likert 1-4, jika total skor yang diperoleh partisipan < 17 skor maka memiliki level moral yang rendah (yang diberi kode 1), namun jika total skor $\geq 17$, maka termasuk level moral yang tinggi (yang diberi kode 2).

Sumber data yang digunakan dalam penelitian ini adalah data primer. Pengertian data primer adalah data yang didapatkan dengan melakukan penelitian langsung terhadap subjek penelitian, dengan cara menggunakan angket, kasus, kuesioner, dan 


\section{JURNAL NOMINAL / VOLUME V NOMOR 2 / TAHUN 2016}

lainnya (Mudrajad Kuncoro, 2013:148). Data primer dalam penelitian ini meliputi jawaban partisipan yang diperoleh dari penyebaran kuesioner tentang studi eksperimen Pengaruh Pengendalian Internal dan Moralitas Individu terhadap Kecurangan Akuntansi pada bagian keuangan dan akuntansi UNY.

Instrumen yang digunakan dalam penelitian ini berupa kasus. Kasus berkaitan dengan variabel terikatnya yaitu Kecurangan Akuntansi, serta variabel bebasnya yaitu Pengendalian Internal (terdapat dan tidak terdapat elemen Pengendalian Internal) dan Moralitas Individu (level moral tinggi dan rendah). Instrumen penelitian ini mengacu pada penelitian Gusti (2014) yang merupakan pengembangan dari instrumen penelitian eksperimen oleh Puspasari (2012). Berdasarkan instrumen penelitian tersebut, peneliti membuat instrumen dengan melakukan modifikasi agar instrumen sesuai dengan variabel yang digunakan peneliti.

Soal penugasan pertama terkait kecenderungan untuk melakukan Kecurangan Akuntansi berada dalam dua kondisi, yaitu terdapat elemen Pengendalian Internal dan tidak terdapat elemen Pengenalian Internal. Selanjutnya partisipan akan menjawab soal penugasan kedua tentang dilema etika. Partisipan kemudian diberi pertanyaan-pertanyaan untuk mengukur level penalaran Moralitas
Individu tersebut berdasarkan skor yang diperoleh.

Variabel Moralitas Individu akan diukur berdasarkan model pengukuran moral oleh Kohlberg (1971) dalam bentuk instrumen Defining Issues Test (DIT) yang dirancang untuk mengukur kapasitas moral kognitif, yaitu tingkat penalaran moral yang mampu dilakukan oleh seorang individu. Instrumen ini berbentuk kasus dilema etika. Moralitas diukur melalui 6 butir instrumen yang mengukur setiap tahapan moralitas melalui kasus dilema etika akuntansi yang dikembangkan lagi dalam penelitian Gusti (2014).

Setiap tahapan moralitas ditunjukkan dengan skala 1-4, kemudian dijumlahkan semua hasil skala tersebut. Skala Likert yang digunakan dalam penilaian Moralitas Individu menggunakan rentang nilai 1-4 untuk menghilangkan jawaban ragu-ragu yang mempunyai makna ganda dan tidak dapat menjelaskan kepastian jawaban dari partisipan. Skala ini memiliki empat alternatif jawaban yaitu SS=Sangat Setuju, S=Setuju, TS=Tidak Setuju, STS=Sangat Tidak Setuju. Jika total skor yang diperoleh partisipan $\geq 17$, maka dapat dikatakan partisipan memiliki level moral yang tinggi (level post-conventional). Namun jika total skor yang diperoleh partisipan < 17 maka partisipan tersebut dapat dikatakan memiliki level moral yang rendah (level preconventional). Setelah itu partisipan akan 


\section{JURNAL NOMINAL / VOLUME V NOMOR 2 / TAHUN 2016}

dikelompokkan berdasarkan empat grup yaitu : Grup 1 (kelompok dalam kondisi terdapat elemen Pengendalian Internal dengan level moral tinggi); Grup 2 (kelompok dalam kondisi tidak terdapat elemen Pengendalian Internal dengan level moral tinggi); Grup 3 (kelompok dalam kondisi terdapat elemen Pengendalian Internal dengan level moral rendah); dan Grup 4 (kelompok dalam kondisi tidak terdapat elemen Pengendalian Internal dengan level moral rendah).

Teknik pengumpulan data yang digunakan dalam penelitian ini adalah dengan menyebarkan kuesioner. Teknik kuesioner yaitu suatu pengumpulan data dengan memberikan atau menyebarkan daftar pertanyaan/pernyataan kepada partisipan dengan harapan memberikan respons atas daftar pertanyaan tersebut (Mudrajad Kuncoro, 2013:183). Kuesioner yang disebarkan berupa soal kasus penelitian eksperimen yang berkaitan dengan objek yang diteliti, kuesioner diberikan disertai dengan surat permohonan izin dan penjelasan mengenai tujuan dari penelitian yang dilakukan tersebut.

\section{Teknik Analisis Data}

\section{1) Pilot Test}

Pilot test bertujuan untuk memberikan kepastian bahwa semua orang yang menjadi partisipan tidak hanya memahami tiap butir pertanyaan atau pernyataan dalam instrumen, tetapi juga mengerti keseluruhan instrumen dengan pemikiran yang sama (Center for Evaluation Research, 2011). Beberapa perubahan terhadap desain awal kuesioner kemungkinan dilakukan dengan masukan yang sesuai dengan tujuan penelitian. Pilot test dilakukan pada 20 orang mahasiswa Akutansi S1 angkatan 2013 di Universitas Negeri Yogyakarta.

\section{2) Uji Instrumen}

Hair et al., (2006) berpendapat bahwa terdapat dua cara yang dapat dipilih dalam uji validitas dan realibilitas, cara pertama yaitu memakai instrumen yang validitas dan reliabilitasnya telah dibuktikan dalam penelitian terdahulu; sedangkan cara kedua yaitu dengan menggunakan instrumen baru yang tingkat validitas dan reliabilitasnya belum diketahui. Peneliti memilih cara pertama yaitu menggunakan instrumen yang sudah teruji validitas dan reliabilitasnya, dengan melakukan pengembangan dari instrumen penelitian Gusti (2014). Namun karena penelitian ini dilakukan di tempat dan partisipan yang berbeda, maka peneliti melakukan uji validitas dan reliabilitas ulang untuk mempertegas hasil penelitian.

\section{a) Uji Validitas}

Validitas suatu instrumen penelitian akan ditentukan oleh proses penelitian yang akurat. Uji validitas dilakukan untuk mengetahui kemampuan suatu alat ukur untuk mengukur apa yang seharusnya diukur. Terdapat dua jenis uji validitas yang digunakan dalam penelitian eksperimen ini. 


\section{JURNAL NOMINAL / VOLUME V NOMOR 2 / TAHUN 2016}

Uji validitas pertama menggunakan face validity untuk mengukur instrumen pada variabel Pengendalian Internal, dengan instrumen berupa kasus. Suatu instrumen penelitian dapat dinilai memiliki face validity jika telah dilakukan penilaian subjektif oleh para profesional, bahwa instrumen tersebut telah merefleksikan secara akurat dan menunjukkan secara logis tentang sesuatu yang seharusnya diukur. Teknik pengukuran instrumen dengan face validity adalah dengan meminta dosen pembimbing untuk membaca instrumen tersebut kemudian meminta masukan dari mereka untuk keperluan revisi. Teknik face validity dirasa peneliti telah cukup untuk mengukur validitas instrumen karena instrumen kasus yang digunakan peneliti hanya mengadopsi dan memodifikasi instrumen terdahulu yang telah diuji validitasnya. Setelah instrumen penelitian diuji validitasnya, peneliti akan memperbaiki bagian instrumen yang kurang valid.

Uji validitas kedua yaitu dengan uji validitas isi (content validity) yang dilakukan pada variabel Moralitas Individu dan Kecurangan Akuntansi dengan cara mengkorelasikan skor tiap butir pernyataan dengan skor total variabel tersebut. Menurut Ghozali (2009:53) pengujian validitas menggunakan signifikansi 0,05 dengan kriteria pengujian sebagai berikut: (a) Apabila $r$ hitung $\geq \mathrm{r}$ tabel maka itemitem pernyataan yang terdapat pada intrumen berkorelasi signifikan terhadap skor total item pernyataan, sehingga item-item pernyataan atau instrumen dapat dinyatakan valid.

(b) Apabila $r$ hitung $<\mathrm{r}$ tabel maka itemitem pernyataan yang terdapat pada intrumen tidak berkorelasi signifikan terhadap skor total item pernyataan, sehingga item-item pernyataan atau instrumen dapat dinyatakan tidak valid.

\section{b) Uji Reliabilitas}

Uji reliabilitas merupakan uji yang digunakan untuk menentukan sejauh mana alat ukur dapat dipercaya dan diandalkan, sehingga dapat mengukur objek yang akan diukur. Tingkat reliabilitas suatu instrumen diukur dengan menghitung besarnya nilai cronbach's alpha. Nilai cronbach's alpha dapat dikatakan reliabel apabila nilai cronbach's alpha lebih besar dari 0,6 (Ghozali, 2009:47).

\section{3) Metode Analisis Data}

Berbagai pengujian data yang dilakukan dalam penelitian ini yaitu meliputi distribusi frekuensi untuk statistik deskriptif, uji homogenitas, dan uji normalitas data. Setelah itu dilakukan analisis varians (ANOVA) untuk menguji hubungan antara satu variabel dependen (skala metrik) dengan satu atau lebih variabel independen (skala nonmetrik atau kategorikal). 


\section{JURNAL NOMINAL / VOLUME V NOMOR 2 / TAHUN 2016}

\section{a) Statistik Deskriptif}

Statistik deskriptif merupakan statistik yang berguna untuk mendeskripsikan objek penelitian melalui data sampel atau populasi sebagaimana adanya, tanpa melakukan proses analisis dan menentukan kesimpulan yang berlaku umum (Sugiyono,2007:29). Data yang digunakan adalah data yang berasal dari rata-rata (mean), standar deviasi, nilai maksimum, nilai minimum, dan jumlah data penelitian. Analisis statistik deskriptif dalam penelitian ini kemudian akan dibagi menjadi dua bagian yaitu statistik deskriptif data demografi partisipan dan statistik deskriptif data variabel. Statistik deskriptif data variabel akan digunakan untuk mengetahui gambaran mengenai karakteristik variabel-variabel penelitian khususnya mean dan deviasi standar yang dibagi dalam empat grup eksperimen. Statistik deskriptif data demografi partisipan di bagian usia akan dikelompokkan dengan tabel distribusi frekuensi. Sugiyono (2007:32) menjelaskan bahwa tabel distribusi frekuensi disusun jika jumlah data yang disajikan cukup banyak sehingga jika disajikan dalam tabel biasa menjadi tidak efisien.

\section{b) Uji Normalitas}

Screening terhadap normalitas data merupakan langkah awal yang harus dilakukan untuk setiap analisis multivariate. Hasil uji statistik akan lebih baik jika semua variabel berdistribusi normal. Jika variabel tidak terdistribusi secara normal, maka hasil uji statistik akan terdegradasi (Ghozali, 2009:29). Uji Kolmogorov Smirnov adalah pengujian normalitas yang banyak dipakai. Kelebihan dari uji ini adalah sederhana dan tidak menimbulkan perbedaan persepsi di antara satu pengamatan dengan pengamatan yang lain, yang sering terjadi pada uji normalitas dengan menggunakan grafik.

\section{c) Uji Homogenitas}

Homogeneity of variance yaitu variabel dependen harus memiliki varian yang sama dalam setiap kategori variabel independen (Ghozali, 2009:70). Jika terdapat lebih dari satu variabel independen, maka harus ada homogeneity of variance di dalam cell yang dibentuk oleh variabel independen kategorikal. SPSS memberikan test ini dengan nama Levene's Test of Homogeneity of Variance. Jika nilai Levene's Test signifikan (probabilitas $<0,05$ ) maka grup memiliki varian yang berbeda dan hal ini menyalahi asumsi. Jadi yang dikehendaki adalah Levene's Test tidak signifikan (probabilitas $\geq 0,05$ ).

\section{d) Uji Hipotesis}

Untuk menguji hipotesis dalam penelitian ini digunakan uji statistik Two Way Analysis of Variance dengan Main Effect dan Interaction Effect menggunakan program SPSS versi 20.0. Peneliti menerapkan taraf signifikansi $5 \%$ dalam penelitian ini. Kriteria untuk pembuatan keputusannya adalah sebagai berikut: Jika 


\section{JURNAL NOMINAL / VOLUME V NOMOR 2 / TAHUN 2016}

nilai signifikansi > 0,05 maka $\mathrm{H}_{0}$ diterima; Jika nilai signifikansi $\leq 0,05$ maka maka $\mathrm{Hi}$ diterima atau menolak $\mathrm{H}_{0}$.

\section{HASIL PENELITIAN DAN} PEMBAHASAN

\section{Deskripsi Data Penelitian}

Data pada penelitian ini dikumpulkan dengan cara menyebarkan kuisioner kepada seluruh pegawai bagian keuangan dan akuntansi di Universitas Negeri Yogyakarta sebanyak 82 kuisioner, namun 9 kuisioner dinyatakan gugur karena pengisian tidak lengkap, sehingga kuisioner yang terkumpul berjumlah 73 kuisioner.

\section{Statistik Deskriptif}

$\begin{array}{rrrr} & \text { Statistik } & \text { deskriptif } & \text { merupakan } \\ \text { statistik yang } & \text { berguna } & \text { untuk }\end{array}$
mendeskripsikan objek yang diteliti melalui data sampel atau populasi sebagaimana adanya (Sugiyono, 2007:29). Statistik deskriptif dalam penelitian ini diukur menggunakan bantuan SPSS Statistics 20.0 For Windows kemudian akan dibagi menjadi dua bagian yaitu statistik deskriptif data demografi partisipan dan statistik deskriptif data variabel. Statistik deskriptif data demografi partisipan bertujuan untuk mengetahui deskripsi usia, jenis kelamin dan lama bekerja dari partisipan penelitian. Statistik deskriptif data variabel bertujuan untuk mengetahui deskripsi variabel yang terdapat dalam penelitian.
Mean dari usia partisipan adalah 41 tahun dengan usia terendah 20 tahun dan usia tertinggi 58 tahun. Frekuensi usia yang paling sering muncul adalah 30 tahun. Standar deviasi pada data usia partisipan adalah 10,573 dengan varians 111,795. Jumlah kelas interval setelah dihitung dengan menggunakan rumus Struges sebanyak 7 kelas, dengan panjang kelas interval 5.

Sebanyak 37 partisipan atau sebesar $50,7 \%$ berjenis kelamin laki-laki sedangkan sebanyak 36 partisipan atau sebesar 49,3\% berjenis kelamin perempuan. Partisipan dengan pengalaman kerja lebih dari 10 tahun mendominasi dengan total 39 partisipan atau sebesar 53,4\%. Sementara itu, pendidikan terakhir yang ditempuh partisipan paling banyak adalah S1 dengan total 53 partisipan atau sebesar $72,6 \%$.

Statistik deskriptif data variabel dalam penelitian ini meliputi mean dan deviasi standar yang disajikan guna memberikan informasi terkait karakteristik variabel penelitian dalam empat grup eksperimen. Pengukuran mean digunakan untuk mengukur nilai tengah distribusi data sedangkan deviasi standar merupakan tingkat penyebaran antara nilai data yang diteliti dengan nilai rata-ratanya. 


\section{JURNAL NOMINAL / VOLUME V NOMOR 2 / TAHUN 2016}

\section{Uji Instrumen}

Teknik pengujian instrumen dilakukan menggunakan uji validitas dan uji reliabilitas agar data yang dihasilkan berkualitas dan dapat dipertanggungjawabkan.

\section{a. Uji Validitas}

Penelitian ini menggunakan dua jenis uji validitas. Uji validitas pertama adalah dengan teknik face validity. Teknik face validity dapat pula disebut validitas fisik karena hanya sekedar penilaian secara subjektif, yang menunjukkan apakah instrumen dari segi fisik dapat mengukur apa yang seharusnya diukur, sehingga validitas ini mengacu pada bentuk dan penampilan instrumen. Teknik face validity digunakan pada variabel Pengendalian Internal, dengan cara meminta orang profesional (dosen pembimbing) untuk membaca kasus dan isi instrumen tersebut. Peneliti menggunakan teknik face validity karena instrumen kasus yang digunakan peneliti hanya mengadopsi dan memodifikasi instrumen terdahulu yang telah diuji validitasnya.

Uji validitas kedua menggunakan uji validitas isi (content validity). Uji validitas isi pada variabel Moralitas Individu dan Kecurangan Akuntansi dilakukan dengan cara mengkorelasikan skor tiap butir pernyataan dengan skor total variabel tersebut. Hasil uji validitas untuk variabel Moralitas Individu sebanyak 6 butir pernyataan dinyatakan valid, sedangkan untuk variabel Kecurangan Akuntansi sebanyak 4 pernyataan juga dinyatakan valid. Pengujian validitas menggunakan signifikansi alpha sebesar 0,05 dengan uji 2 sisi dan jumlah data $(\mathrm{n})=73$. Uji signifikansi dilakukan dengan membandingan nilai $r$ hitung dengan $r$ tabel untuk perhitungan degree of freedom $(\mathrm{df})=$ $\mathrm{n}-2$, dengan $\mathrm{n}$ sebagai jumlah partisipan. Pada penelitian ini, variabel Moralitas Individu dan Kecurangan Akuntansi mempunyai jumlah partisipan $(\mathrm{n})=73$, sehingga besarnya df dapat dihitung : 73-2 = 71, maka dapat diketahui $\mathrm{r}$ tabel sebesar 0,230. Kriteria pengujian sebagai berikut (Ghozali, 2009:53):

1) Apabila $r$ hitung $\geq r$ tabel maka item-item pernyataan yang terdapat pada intrumen berkorelasi signifikan terhadap skor total item pernyataan, sehingga item-item pernyataan atau instrumen dapat dinyatakan valid.

2) Apabila $r$ hitung $<r$ tabel maka item-item pernyataan yang terdapat pada intrumen tidak berkorelasi signifikan terhadap skor total item pernyataan, sehingga item-item pernyataan atau instrumen dapat dinyatakan tidak valid.

\section{b. Uji Reliabilitas}

Suatu kuisioner dapat dikatakan reliabel atau handal jika jawaban partisipan terhadap pernyataan konsisten dari waktu ke waktu. Peneliti akan menguji reliabilitas variabel Moralitas Individu dan variabel 


\section{JURNAL NOMINAL / VOLUME V NOMOR 2 / TAHUN 2016}

Kecurangan Akuntansi dengan melihat nilai cronbach's alpha. Nilai cronbach's alpha instrumen variabel Moralitas Individu sebesar 0,794 dari 6 pertanyaan. Sementara itu, nilai cronbach's alpha instrumen variabel Kecurangan Akuntansi adalah 0,731 dari 4 item pernyataan sehingga dapat disimpulkan bahwa semua item tersebut reliabel. Tingkat reliabilitas suatu instrumen diukur dengan menghitung besarnya nilai cronbach's alpha. Nilai cronbach's alpha dapat dikatakan reliabel apabila nilai cronbach's alpha lebih besar dari 0,6 (Ghozali, 2009:48).

\section{Uji Asumsi Klasik}

Untuk dapat menggunakan uji statistik Analysis of Variance (ANOVA) harus dipenuhi beberapa asumsi yaitu : multivariate normality, subjek setiap grup diambil secara random, dan homogeneity of variance. Oleh sebab itu, diperlukan uji normalitas dan uji homogenitas untuk dapat memakai ANOVA. Berikut adalah penjabaran uji asumsi klasik yang digunakan:

\section{a. Uji Normalitas}

Uji normalitas dilakukan untuk mengetahui apakah data dalam penelitian ini terdistribusi dengan normal. Uji normalitas diperlukan untuk memenuhi salah satu asumsi analysis of variance (ANOVA). Berikut adalah uji normalitas variabel dependen, Kecurangan Akuntansi dengan Kolmogorov-Smirnov Test:
Tabel 2. Uji Normalitas

\begin{tabular}{llr}
\hline \multicolumn{3}{c}{ One-Sample Kolmogorov-Smirnov Test } \\
\hline \multirow{2}{*}{ N } & \multicolumn{2}{c}{ KECURANG } \\
AN \\
AKUNTANSI \\
\hline Normal Parameters ${ }^{\text {a,b }}$ & Mean & 73 \\
\cline { 2 - 3 } & Std. Deviation & 24,08 \\
\hline \multirow{2}{*}{ Most Extreme Differences } & Absolute & 7,626 \\
\cline { 2 - 3 } & Positive &, 077 \\
\cline { 2 - 3 } & Negative &, 077 \\
\hline Kolmogorov-Smirnov Z & &,- 075 \\
\hline Asymp. Sig. (2-tailed) & &, 658 \\
\hline a. Test distribution is Normal. &, 779 \\
\hline b. Calculated from data. & \\
\hline
\end{tabular}

Sumber : Data Primer yang Diolah

Variabel dependen, yaitu Kecurangan Akuntansi diharapkan terdistribusi secara normal dalam setiap kategori variabel independen (Ghozali, 2009:70). Hasil pengujian normalitas dengan KolmogorovSmirnov Test menunjukkan nilai Asymp. Sig adalah 0,779 dan di atas nilai 0,05. Hal tersebut menunjukkan bahwa data terdistribusi dengan normal dan memenuhi salah satu asumsi analysis of variance (ANOVA).

\section{b. Uji Homogenitas}

Levene's test dilakukan untuk mengetahui apakah perlakuan dalam empat grup mempunyai varian yang sama. Uji homogenitas digunakan agar subjek mempunyai varian yang sama guna memenuhi asumsi analysis of variance (ANOVA). Berikut adalah hasil uji homogenitas dengan levene's test: 


\section{JURNAL NOMINAL / VOLUME V NOMOR 2 / TAHUN 2016}

Tabel 3. Uji Homogenitas

Levene's Test of Equality of

Error Variances ${ }^{\mathrm{a}}$

Dependent Variable:

KECURANGAN

AKUNTANSI

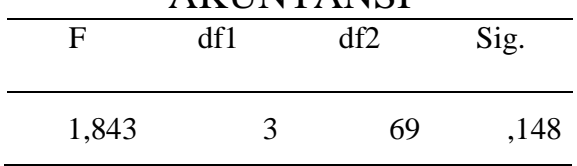

Sumber : Data Primer yang Diolah

Hasil uji statistik dalam tabel menunjukkan nilai Sig. levene's test sebesar 0,148 dan mempunyai nilai di atas 0,05 . Hal ini menunjukkan bahwa setiap kelompok subjek memenuhi varian yang sama. Oleh sebab itu, dapat disimpulkan bahwa telah memenuhi asumsi ANOVA (Hair et al., 2006).

\section{Uji Hipotesis}

a. Two-Way Analysis of Variance (ANOVA)

Tahap terakhir analisis dalam penelitian ini adalah melakukan pengujian data yang mengacu pada hipotesis penelitian yang diajukan. Pengujian hipotesis-hipotesis penelitian menggunakan Two-Way Analysis of Variance (ANOVA) dan dilakukan pada batas signifikansi 5\% atau dengan tingkat kepercayaan sebesar 95\%. Hasil analisis varian desain faktorial yang dapat digunakan untuk membuktikan ketiga macam hipotesis tersebut yaitu disajikan pada tabel berikut :

Tabel 4. Uji Hipotesis dengan Two-Way ANOVA
Dependent Variable: Kecurangan Akuntansi

\begin{tabular}{lccc}
\hline \multicolumn{1}{c}{ Variabel } & $\mathrm{F}$ & Sig & Ket \\
\hline $\begin{array}{l}\text { Pengendalian } \\
\text { Internal }\end{array}$ & 13,871 &, 000 & $\begin{array}{c}\mathrm{H} 1 \\
\text { Diterima }\end{array}$ \\
\hline $\begin{array}{l}\text { Moralitas } \\
\text { Individu }\end{array}$ & 17,592 &, 000 & $\begin{array}{c}\mathrm{H} 2 \\
\text { Diterima }\end{array}$ \\
\hline $\begin{array}{l}\text { Pengendalian } \\
\text { Internal } \\
\text { Moralitas } \\
\text { Individu }\end{array}$ & 18,990 &, 000 & $\mathrm{H} 3$ \\
& & & Diterima \\
& & &
\end{tabular}

Sumber : Data Primer yang Diolah

Menurut Ghozali (2009:84) Kriteria untuk pembuatan keputusannya adalah sebagai berikut:

1) Jika nilai signifikansi $>0,05$ maka $\mathrm{H}_{0}$ diterima

2) Jika nilai signifikansi $\leq 0,05$ maka maka $\mathrm{Hi}$ diterima atau menolak $\mathrm{H}_{0}$

Hasil analisis pada tabel tersebut menunjukkan bahwa nilai koefisien Sig. untuk hipotesis 1, 2, dan 3 (Hipotesis efek perlakuan Pengendalian Internal, efek perlakuan Moralitas Individu serta efek interaksi antara Pengendalian Internal dan Moralitas Individu) seluruhnya lebih kecil dari nilai alpha yang ditetapkan, yaitu 0,05.

1) $\mathrm{H}_{1}$ yang menyatakan bahwa terdapat perbedaan antara individu pada kondisi terdapat elemen Pengendalian Internal dan tidak terdapat elemen Pengendalian Internal dalam melakukan Kecurangan Akuntansi diterima. Hal ini dapat dilihat dari hasil nilai $F$ sebesar 13,871 dan signikansi sebesar 0,000 . 


\section{JURNAL NOMINAL / VOLUME V NOMOR 2 / TAHUN 2016}

2) $\mathrm{H}_{2}$ yang menyatakan bahwa terdapat perbedaan antara individu yang memiliki level Moralitas Individu tinggi dan level Moralitas Individu rendah dalam melakukan Kecurangan Akuntansi diterima. Hal ini dapat dilihat dari hasil nilai $\mathrm{F}$ sebesar 17,592 dan signikansi sebesar 0,000 .

3) $\mathrm{H}_{3}$ yang menyatakan bahwa terdapat interaksi antara Pengendalian Internal dengan Moralitas Individu dalam mempengaruhi Kecurangan Akuntansi diterima. Hal ini dapat dilihat dari hasil nilai $\mathrm{F}$ sebesar 18,990 dan signikansi sebesar 0,000 .

\section{SIMPULAN DAN SARAN}

\section{Simpulan}

Penelitian ini bertujuan membandingkan kecenderungan seseorang melakukan Kecurangan Akuntansi dalam kondisi terdapat elemen Pengendalian Internal dan tidak terdapat elemen Pengendalian Internal antara seseorang dengan level penalaran Moralitas Individu tinggi dan seseorang dengan level penalaran Moralitas Individu rendah. Partisipan dari penelitian ini adalah sebanyak 73 orang pegawai bagian keuangan dan akuntansi Universitas Negeri Yogyakarta. Pengujian hipotesis penelitian ini dilakukan dengan uji two way ANOVA. Berdasarkan pengujian tersebut dapat disimpulkan bahwa: a. Terdapat perbedaan antara individu yang berada dalam kondisi terdapat elemen Pengendalian Internal maupun tidak terdapat elemen Pengendalian Internal dalam melakukan Kecurangan Akuntansi. Hasil nilai signifikansi Pengendalian Internal adalah 0,000 sedangkan F hitung sebesar 13,871. Kriteria hipotesis diterima adalah signifikansi kurang dari 0,05 sehingga dapat disimpulkan $\mathrm{H} 1$ diterima.

b. Terdapat perbedaan antara individu yang memiliki level Moralitas Individu tinggi dan level Moralitas Individu rendah dalam melakukan Kecurangan Akuntansi. Hasil nilai signifikansi Pengendalian Internal adalah 0,000 sedangkan $\mathrm{F}$ hitung sebesar 17,592. Kriteria hipotesis diterima adalah signifikansi kurang dari 0,05 sehingga dapat disimpulkan $\mathrm{H} 2$ diterima.

c. Terdapat interaksi antara Pengendalian Internal dengan level Moralitas Individu. Artinya perubahan pada kondisi Pengendalian Internal atau pada satu level faktor Moralitas Individu, akan menyebabkan perubahan individu dalam melakukan Kecurangan Akuntansi. Hasil nilai signifikansi Pengendalian Internal adalah 0,000 sedangkan $\mathrm{F}$ hitung sebesar 18,990. Kriteria hipotesis diterima adalah signifikansi kurang dari 0,05 sehingga dapat disimpulkan $\mathrm{H} 3$ diterima. 


\section{JURNAL NOMINAL / VOLUME V NOMOR 2 / TAHUN 2016}

\section{Saran}

Berdasarkan simpulan dan keterbatasan yang dihadapi, maka berikut ini beberapa saran yang dapat dipertimbangkan bagi instansi adalah sebagai berikut: 1) Perlu dilakukan evaluasi secara berkala untuk mengetahui apakah Pengendalian Internal yang terdapat dalam instansi telah berjalan dengan baik; 2) Moralitas Individu dari para karyawan perlu ditingkatkan dengan internalisasi nilai-nilai karakter dan budaya organisasi yang baik agar karyawan dapat bekerja secara jujur dan menghindari tindakan untuk melakukan Kecurangan Akuntansi.

Bagi peneliti selanjutnya saran yang dapat pertimbangkan adalah sebagai berikut: 1)Penelitian selanjutnya diharapkan dapat menggunakan variabel-variabel independen seperti sistem kompensasi, ketaatan aturan akuntansi, perilaku tidak etis atau variabel lain yang mempengaruhi kecenderungan seseorang untuk melakukan Kecurangan Akuntansi. Selain itu juga dapat memasukkan variabel-variabel yang terkait data demografis partisipan seperti jenis kelamin, pendidikan terakhir, posisi di organisasi, usia atau yang lain sehingga pilihan kasus dalam desain eksperimen lebih bervariasi; 2) Penelitian sebaiknya dikembangkan dengan memilih instansi yang memiliki populasi lebih baik dalam bentuk kuantitas maupun kualitas yang disesuaikan dengan tujuan penelitian;
3)Penelitian selanjutnya juga diharapkan untuk lebih fokus pada desain eksperimen murni yang lebih baik agar dapat menggambarkan kondisi yang lebih nyata.

\section{DAFTAR PUSTAKA}

Albrecht, W.Steve. (2014). "Iconic Fraud Triangle Endures”. Fraud Magazines. Hlm.3-5.

Associations of Certified Fraud Examinations (ACFE). (2014). Report to the Nations on Occupatuional Fraud and Abuse - 2014 Global Study Fraud. USA : Association of Certified Fraud Examiners, Inc.

Badan Pemeriksa Keuangan Republik Indonesia (BPK RI). (2007). Peraturan Badan Pemeriksa Keuangan No. 01 Tahun 2007 : Standar Pemeriksaan Keuangan Negara. Jakarta : Badan Pemeriksa Keuangan Republik Indonesia.

Elder, Randal J. et al. (2012). Jasa Audit dan Assurance : Pendekatan Terpadu (Adaptasi Indonesia). (Alih bahasa : Desti Fitriani). Jakarta : Salemba Empat.

Ghozali, I. (2009). Aplikasi Analisis Multivariate Dengan Program IBM SPSS 19. Edisi Keenam. Semarang : Penerbit Universitas Diponegoro.

Gould, Jay E. (2002). Concise Handbook Of Experimental Methods For The Behavioral And Biological Sciences. Boca Raton, Florida : CRC Press LLC.

Gusti Ayu Ketut Rencana Sari Dewi. (2014). "Pengaruh Moralitas Individu Dan Pengendalian Internal Pada Kecurangan Akuntansi (Studi Eksperimen Pada Pemerintah Daerah Provinsi Bali)". Tesis. Program Studi 


\section{JURNAL NOMINAL / VOLUME V NOMOR 2 / TAHUN 2016}

Akuntansi Program Pascasarjana Universitas Udayana Denpasar.

Hair, J.F. JR., Anderson, Tatham, dan Black. (2006). Multivariate Data Analysis. Sixth Edition. New Jersey: Pearson.

Indonesia Corruption Watch (ICW). (2013). "Satu Dasawarsa Pemberantasan Korupsi Pendidikan, 2003-2013, 29 Agustus 2013". Diakses melalui http://www.antikorupsi.org/en/content /rapor-merah-sepuluh-tahun-korupsipendidikan pada tanggal 12 September 2015, pukul 12.35 WIB.

Kabarkorupsi.com. (2014). "Pengelola Aset Perguruan Tinggi Negeri Rawan Terjerat Kasus Korupsi”. Diakses melalui http://kabarkorupsi.com/pengelolaaset-perguruan-tinggi-negeri-rawanterjerat-kasus-korupsi/ pada tanggal 1 Desember 2015 pukul 09.20 WIB.

Kohlberg, Lawrence. (1971). "Stages of Moral Development". Diakses melalui http://info.psu.edu.sa/psu/maths/Stage s\%20of\%20Moral\%20Development\% 20According\%20to\%20Kohlberg.pdf pada tanggal 16 November 2016 pukul 12.42 WIB.

Mudrajad Kuncoro. (2013). Metode Riset untuk Bisnis \& Ekonomi Edisi 4. Jakarta : Penerbit Erlangga.

Olivia Lewi Pramesti (2010). "Korupsi di DIY peringkat 10". Diambil dari http://www.harianjogja.com/baca/201 0/03/11/korupsi-di-diy-peringkat-10138393 pada tanggal 6 Desember 2015, pukul 10.58 WIB.

Puspasari (2012). "Pengaruh Moralitas Individu dan Pengendalian Internal terhadap Kecenderungan Kecurangan Akuntansi: Studi Eksperimen pada Konteks Pemerintahan Daerah”. Tesis.
Program Pasca Sarjana Universitas Gajah Mada.

Sugiyono. (2007). Statistika untuk Penelitian. Bandung : CV Alvabeta.

Transparency International Indonesia. (2014). "Corruption Perception Index 2014". Diakses melalui http://ti.or.id/cpi/materi_tii.pdf pada tanggal 10 Oktober 2015 pukul 20.40 WIB. 